\title{
The use of chiral anionic Co(III) complexes as inhibitors of corrosion and hydrogen absorption in water-salt media containing biogenic hydrogen sulfide
}

\author{
S.M. Beloglazov, ${ }^{+1}$ V.A. Zelentsova, ${ }^{2 * A . G . ~ B e r e z h n a y a, ~}{ }^{3}$ L.G. Knyazeva ${ }^{4}$ \\ and G.S. Beloglazov 5
}

${ }^{1}$ Immanuel Kant Baltic Federal University, 236041 Kaliningrad, Russian Federation

${ }^{2}$ Kaliningrad Regional Institute of the educational development, 236016 Kaliningrad, Russian Federation

${ }^{3}$ Southern Federal University, ul. Zorge 7, Rostov-on-Don, 344090 Russian Federation

${ }^{4}$ All-Russian scientific research institute for the use of machinery and oil products in

agriculture, 392022 Tambov, Russian Federation

${ }^{5}$ Sarasas International School, Bangkok, Thailand

*E-mail: bepoinka@bk.ru

\begin{abstract}
In this report we present the results of experimental and theoretical studies of organic compounds (OC) - chiral anionic complexes of $\mathrm{Co}(\mathrm{III})$ - as inhibitors of corrosion and hydrogen absorption of mild steel. We also estimated the bactericidal effect of organic compounds on sulfate-reducing bacteria (SRB). It was of interest to evaluate the corrosiveness of SRB in the presence of the organic compounds studied in the corrosive environment. The water-salt medium Postgate B that is favorable for the development of SRB was used as an corrosive medium. SRB that directly participate in the electrochemical process are the main causative agents of steel corrosion. Experimental data on the efficiency of the compounds studied as corrosion inhibitors and as inhibitors of hydrogen absorption by mild steel in Postgate $\mathrm{B}$ water-salt medium in the presence of sulfate-reducing bacteria are compared with theoretical results on the calculation of some quantum-chemical parameters. To interpret the experimental results obtained, we performed ab initio (MP/2), MNDO, PM/3, and AM/1 quantum chemical calculations using the Gaussian 03 software package. The values of the following quantumchemical descriptors for the studied compounds were determined: the energies of the boundary orbitals (HOMO and LUMO) [13] and the moduli of the dipole moments for the isolated molecules of each inhibitor. The results obtained showed that OC4, OC5, OC8, and OC9 are the most efficient inhibitors of corrosion and hydrogenation with a bactericidal effect on SRB. The protective effect in gravimetric tests for these compounds is $90-93 \%$. They reduce the hydrogen content at a depth of 30 microns 1.8-2.8 fold. The number of SRB cells is reduced 2-3 fold, depending on the exposure time. The descriptors obtained by quantum-chemical calculations confirm the experimental data.
\end{abstract}

Keywords: organic inhibitors of corrosion and hydrogen absorption, mild steel, sulfatereducing bacteria, biocide, quantum-chemical calculations, dipole moment. 


\section{Introduction}

Despite the widespread use of various polymers in industry, steel is still one of the main structural materials. Therefore, the interest in the study of its corrosion-electrochemical behavior in various environments and in the search for efficient anticorrosive materials for its protection does not subside.

It is known that in the presence of bacteria and various products of microorganisms, an environment becomes corrosive, i.e., active. The bacterial damage of metals and industrial materials constitutes a significant part of the total biodestruction.

Today, it is important to search for efficient corrosion inhibitors that provide a high anticorrosive effect even at low concentrations and are applicable in corrosive environments. They should not only inhibit corrosion processes [1-8] and reduce the hydrogen content in carbon steel samples [4-8] but also cause a bactericidal effect on sulfate-reducing bacteria (SRB) [8]. To this end, modern quantum-chemical calculation methods are called upon to predict the properties of individual chemical compounds and explain their bioactivity. The use of state-of-the-art software significantly accelerates the selection of new compounds with desired properties and makes it possible to ensure that their laborious and expensive synthesis will be expedient [6,7]. This work presents 12 chiral anionic complexes of Co(III), which are coordination-saturated complexes of cobalt(III) with two perpendicularly located tridentate ligands, Schiff bases of salicylic acid (5-Br-salicylic aldehyde) and ( $S$ )-amino acids: glycine, leucine, glutamine, histidine, valine, asparagine (Table 1). The compounds under study were synthesized by V.A. Zelentsova, a postgraduate student at the Immanuel Kant Baltic Federal University in Kaliningrad, under the leadership of Ph.D. A.G. Bulychev. The resulting compositions and molecular structures were confirmed by IR and NMR spectroscopy immediately after the compounds were synthesized. We assumed that the test compounds may be regarded not only as inhibitors of corrosion and hydrogen absorption but also as biocides.

Table 1. The organic compounds (OC) studied.

\begin{tabular}{cccc}
\hline Symbol & Names of organic compounds & Structural formulas & $\mathbf{M} \mathbf{g} / \mathbf{M o l}$ \\
\hline $\mathrm{OC} 1$ & $\begin{array}{c}\Delta, L \text {-bis-( } N \text {-salicylideneglycinato- } \\
\text { cobaltate) sodium }\end{array}$ & \\
$\mathrm{OC} 2 \quad \Delta, L$-bis-( $N$-salicylidenevalinato-cobaltate $)$ \\
sodium
\end{tabular}




\begin{tabular}{|c|c|c|c|}
\hline Symbol & Names of organic compounds & Structural formulas & $\mathbf{M}, \mathbf{g} / \mathbf{M o}$ \\
\hline OC3 & $\begin{array}{l}\Delta, \text { L-bis-(N-salicylideneleucinato- } \\
\text { cobaltate) sodium }\end{array}$ & & 548 \\
\hline $\mathrm{OC} 4$ & $\begin{array}{c}\Delta, L \text {-bis- }(N \text { - } \\
\text { salicylideneasparoginetocobaltate }) \\
\text { sodium }\end{array}$ & & 546 \\
\hline OC5 & $\begin{array}{c}\Delta, L \text {-bis- }(N- \\
\text { salicylideneglutaminocobaltate) sodium }\end{array}$ & & 580 \\
\hline OC6 & $\begin{array}{c}\Delta, L \text {-bis- }(N- \\
\text { salicylidenehistidinatocobaltate) sodium }\end{array}$ & & 596 \\
\hline
\end{tabular}

OC7 $\quad \begin{gathered}\Delta, L \text {-bis- }(N \text {-5Br-salicylidene } \\ \text { glycinatenatocobaltate) sodium }\end{gathered}$

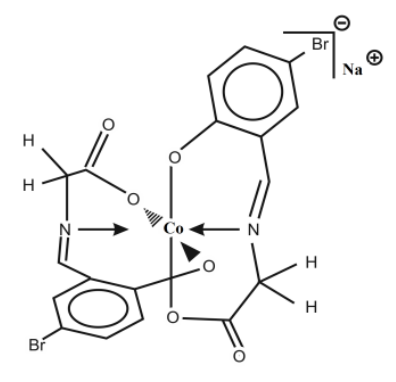

OC8 $\quad \begin{gathered}\Delta, L \text {-bis-( }(N-5 \mathrm{Br}- \\ \text { salicylidenevalonatocobaltate) sodium }\end{gathered}$

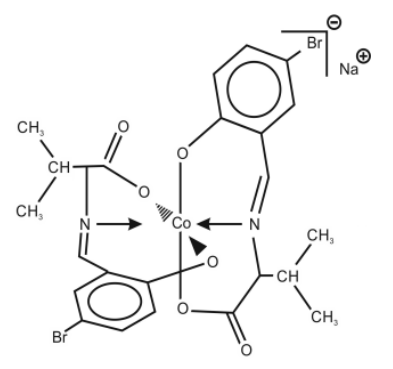




\begin{tabular}{|c|c|c|c|}
\hline Symbol & Names of organic compounds & Structural formulas & M, g/Mol \\
\hline OC9 & $\begin{array}{c}\Delta, L \text {-bis- }(N-5 \mathrm{Br}- \\
\text { salicylidenecinatocobaltate }) \text { sodium }\end{array}$ & & 706 \\
\hline OC10 & $\begin{array}{c}\Delta, L \text {-bis- }(N-5 \mathrm{Br}- \\
\text { salicylideneasproginatocobaltate) sodium }\end{array}$ & & 704 \\
\hline OC11 & $\begin{array}{c}\Delta, L \text {-bis- }(N-5 \mathrm{Br}- \\
\text { salicylideneglutaminocobaltate }) \text { sodium }\end{array}$ & & 738 \\
\hline OC12 & $\begin{array}{c}\Delta, L \text {-bis- }(N-5 \mathrm{Br}- \\
\text { salicylidenehistidinatonatocobaltate }) \\
\text { Sodium }\end{array}$ & & 754 \\
\hline
\end{tabular}

\section{Methods}

The corrosion behavior of flat specimens of mild steel (composition: Fe 98.36; C 0.2; Mn 0.5 ; Si 0.15; P 0.04: S 0.05; Cr 0.3; $\mathrm{Ni} 0.2 ; \mathrm{Cu} 0.2$ ) with a surface area of $20 \mathrm{~cm}^{2}$ was studied. A Postgate B water-salt solution was used as the corrosive medium that supports the growth of anaerobic SRB of Desulfovibrio desulfuricans genus, in the presence of which corrosion processes are sharply enhanced. Air-tight sealed tubes with the samples were placed in a thermostat $(310 \mathrm{~K})$. The bacterial titer was monitored daily. At the end of the exposure (200 $\mathrm{h}$ ), the corrosion rate of steel was determined by the gravimetric method. The protective effect $(Z)$ of the test substances was calculated using the formula:

$$
Z=\left(K_{0}-K\right) / K_{0} \cdot 100 \%,
$$

where $K_{0}$ and $K$ are the corrosion rates of steel in the absence and presence of corrosion inhibitors. 
Electrochemical polarization studies were carried out in a three-electrode thermostatted $\left(25 \pm 0.5^{\circ} \mathrm{C}\right)$ cell with separated anode and cathode spaces using P-5827, PI-50-1.1 and IPC2000 potentiostat-galvanostats. The potential was monitored and the current was recorded using a V7-35 combined digital device. Polarization curves were recorded by changing the potential stepwise at $20 \mathrm{mV}$ steps and an exposure of 60 seconds. The results of polarization measurements are presented relative to an EVL-1M saturated silver chloride electrode. A platinum counter electrode was used.

The distribution of hydrogen absorbed by the surface layer as a function of depth was obtained by layer-by-layer dissolution of mild steel samples. Based on these data, the efficiency of the compounds as hydrogen absorption inhibitors was determined [9].

To interpret the obtained experimental results, we performed $a b$ initio quantum chemical calculations by the (MP/2), MNDO, PM/ 3 and AM/1 methods $[10,11]$ using the Gaussian 03, Revision B.05 software package [12]. The values of the following quantumchemical descriptors for the studied compounds were determined: the energies of the boundary orbitals (HOMO and LUMO) [13] and the moduli of the dipole moments for the isolated molecules of each inhibitor.

\section{Results and Discussion}

The results of gravimetric studies on the efficiency of the studied chiral anionic complexes $\mathrm{Co}$ (III) as inhibitors of corrosion of mild steel in water-salt Postgate B solution (at concentrations of $1,2,5,10 \mathrm{mmol} / \mathrm{L}$ ) are presented in Table 2 . An increase in the concentration of the compounds in question resulted in an increase in their protective action. In complexes with salicylic aldehyde (OC1-OC6), the minimum protective effect was observed at the lowest concentration studied $(1 \mathrm{mmol} / \mathrm{L})$. In the case of $\mathrm{OC} 2$ with a molecular weight of $492 \mathrm{~g} / \mathrm{mol}$, it was $45.9 \%$. This compound has the lowest protective effect of all the compounds studied. The maximum protective effect in this group (89.9\%) was provided by OC5 with a molecular weight of $580 \mathrm{~g} / \mathrm{mol}$ at a concentration of $10 \mathrm{mmol} / \mathrm{L}$.

Table 2. Effect of OC concentration on the protective efficiency.

Concentration of OC1-OC12, $\mathrm{mmol} / \mathrm{L}$

Chiral anionic complexes of $\mathrm{Co}(\mathrm{III})$

\begin{tabular}{cccc}
\hline $\mathbf{1}$ & $\mathbf{2}$ & $\mathbf{5}$ & $\mathbf{1 0}$ \\
\hline \multicolumn{4}{c}{ Protective effect $\boldsymbol{-} \boldsymbol{Z}, \boldsymbol{\%}$} \\
\hline 67.7 & 73.3 & 73.0 & 75.9 \\
45.9 & 63.0 & 63.6 & 66.6 \\
69.6 & 78.5 & 85.1 & 87.5 \\
74.8 & 85.5 & 87.9 & 89.7 \\
74.9 & 84.6 & 88.6 & 89.9 \\
\hline
\end{tabular}




\section{Concentration of $\mathrm{OC1}-\mathrm{OC12}, \mathrm{mmol} / \mathrm{L}$}

Chiral anionic complexes of $\mathrm{Co}(\mathrm{III})$

\begin{tabular}{cccc}
\hline $\mathbf{1}$ & $\mathbf{2}$ & $\mathbf{5}$ & $\mathbf{1 0}$ \\
\hline \multicolumn{4}{c}{ Protective effect $\mathbf{-} \boldsymbol{Z}, \boldsymbol{\%}$} \\
84.9 & 73.1 & 85.1 & 87.3 \\
86.1 & 86.3 & 86.7 & 88.9 \\
82.3 & 85.1 & 88.8 & 92.8 \\
82.5 & 85.2 & 88.5 & 93.1 \\
86.3 & 86.8 & 87.6 & 88.0 \\
82.6 & 83.1 & 84.1 & 88.7 \\
74.3 & 75.8 & 80.7 & 81.1 \\
\hline
\end{tabular}

Based on the degree of the metal corrosion protection, the compounds of this group can be arranged in the series:

$$
\text { OC5 }>\text { OC4 }>\text { OC } 3>\text { OC } 1>\text { OC6 }>\text { OC2 }
$$

The data of gravimetric tests qualitatively confirm the results of electrochemical studies (Figure 1, Table 3): the protective effects lie in the same series as above (1).

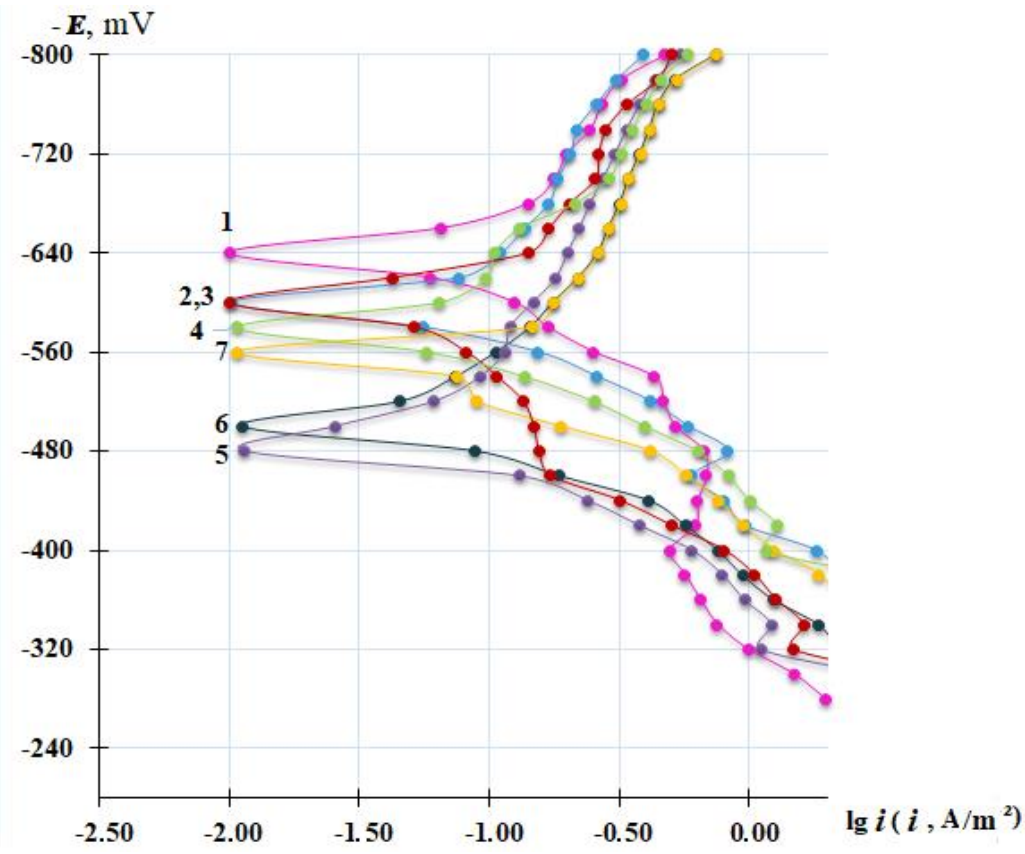

Figure 1. Potentiostatic polarization curves of mild steel in Postgate B water-salt solution: 1 - blank; 2 - OC1;3 - OC2; 4 - OC $3 ; 5$ - OC4; 6 - OC5; 7 - OC6. The concentration of OC $1-\mathrm{OC} 6$ is $1 \mathrm{mmol} / \mathrm{L}$. 
Table 3. Results of electrochemical measurements on mild steel.

\begin{tabular}{cccc}
\hline $\begin{array}{c}\text { Chiral anionic complexes of Co(III) (OC1-OC12 } \\
\text { concentration }=\mathbf{1} \mathbf{~ m m o l} / \mathbf{L})\end{array}$ & $-\boldsymbol{E}_{\mathbf{c o r}}, \mathbf{m V}$ & $\begin{array}{c}\boldsymbol{i}_{\text {cor, }}, \\
\mathbf{A} / \mathbf{m}^{2}\end{array}$ & $\begin{array}{c}\boldsymbol{Z}, \\
\boldsymbol{\%}\end{array}$ \\
\hline Blank & 640 & 0.089 & - \\
OC1 & 600 & 0.063 & 30 \\
OC2 & 600 & 0.079 & 11 \\
OC3 & 580 & 0.045 & 50 \\
OC4 & 480 & 0.042 & 53 \\
OC5 & 500 & 0.028 & 68 \\
OC6 & 560 & 0.062 & 29 \\
OC7 & 600 & 0.038 & 57 \\
OC8 & 480 & 0.035 & 61 \\
OC9 & 500 & 0.031 & 65 \\
OC10 & 560 & 0.041 & 53 \\
OC11 & 600 & 0.039 & 56 \\
OC12 & 520 & 0.066 & 26 \\
\hline
\end{tabular}

The use of complexes with 5-Br-salicylic aldehyde provides a higher level of protection in gravimetric tests. The minimum protective effect $(82.3 \%)$ at a concentration of $1 \mathrm{mmol} / \mathrm{L}$ is provided by OC8 compound with a molecular weight of $650 \mathrm{~g} / \mathrm{mol}$, while the maximum effect $(93.1 \%)$ at a concentration of $10 \mathrm{mmol} / \mathrm{L}$ is provided by OC9 with a molecular weight of $706 \mathrm{~g} / \mathrm{mol}$. Similar results were obtained in electrochemical studies (Table 3). In general, according to the degree of the metal corrosion protection, both in gravimetric studies and in electrochemical studies, the compounds of this group can be arranged in the series:

$$
\text { OC } 9>\text { OC } 8>\text { OC7 }>\text { OC } 11>\text { OC } 10>\text { OC12 }
$$

Chiral anionic complexes of $\mathrm{Co}(\mathrm{III})$ are rather complex compounds. It was interesting to determine the relationship between their structure and the properties under consideration by means of quantum chemical calculations. The energies of the highest occupied molecular orbital $\left(\mathrm{E}_{\mathrm{HOMO}}\right)$ and the lowest unoccupied molecular orbital $\left(\mathrm{E}_{\mathrm{LUMO}}\right)$ and the dipole moments were calculated as descriptors of the reactivity of the molecules studied. The data obtained are shown in Table 4.

High dipole moments of the compounds under study (Table 4) indicate the antisymmetry of their electronic structure, from which one can assume a significant potential reactivity. If the complexes with salicylic aldehyde (OC1-OC6) are arranged in descending order of their dipole moments, it matches the series (1) that reflects the variation in their protective effects toward St3 steel. A similar picture is observed for chiral anionic complexes 
with 5-Br-salicylic aldehyde. The series of decreasing dipole moments in this case generally matches the series (2) of changes in the protective effects toward mild steel.

The effect of the chiral anionic complexes studied on the suppression of SRB can be assessed by the values of the energy difference between the $E_{\mathrm{HOMO}}$ and $E_{\mathrm{LUMO}}$ descriptors (Table 4). All the values obtained are in the range of $0.09-0.23$ in absolute value and have a negative sign, which indicates the biological activity of the compounds under study and is expressed in the suppression of SRB growth. This is experimentally confirmed by the data on the variation in the bacterial titer in the presence of the studied $\mathrm{OC}$ in the medium (Figure 2). The most active compounds are OC4, OC5 in the first series and OC8, OC9 in the second series.

Table 4. Descriptors of reactivity of the molecules of the Co(III) chiral anionic complexes studied.

\begin{tabular}{ccccc}
\hline $\begin{array}{c}\text { OC } \\
\text { designation }\end{array}$ & Dipole moment, D & $\boldsymbol{E H O M O}_{\text {H.u.e. }}$ & $\boldsymbol{E}$ Lumo, a.u.e. & $\Delta \boldsymbol{E}$, a.u.e. \\
\hline OC 1 & 12.1 & -0.22 & 0.01 & -0.23 \\
OC 2 & 7.1 & -0.07 & 0.09 & -0.16 \\
OC 3 & 14.2 & -0.03 & 0.08 & -0.11 \\
OC 4 & -0.02 & 0.07 & -0.09 \\
OC 5 & 18.7 & -0.015 & 0.08 & -0.095 \\
OC 6 & 19.9 & -0.10 & 0.12 & -0.22 \\
OC 7 & 8.8 & -0.14 & 0.08 & -0.22 \\
OC 8 & 13.3 & -0.02 & 0.03 & -0.05 \\
OC 9 & 13.8 & -0.04 & 0.10 & -0.14 \\
OC 10 & 18.9 & -0.07 & 0.06 & -0.13 \\
OC 11 & 8.6 & -0.01 & 0.05 & -0.06 \\
OC 12 & 9.0 & -0.2 & 0.02 & -0.22 \\
\hline
\end{tabular}

The same compounds showed the most efficient protection against hydrogen saturation. The hydrogen content in the tested steel samples at a depth of $30 \mu \mathrm{m}$ decreases depending on the OC4 concentration 2.82-fold on average compared to the hydrogen content in the sample in its absence. The decrease is 2.13-fold in the presence of OC5, 2-fold with OC8, and 1.77-fold with OC9. 

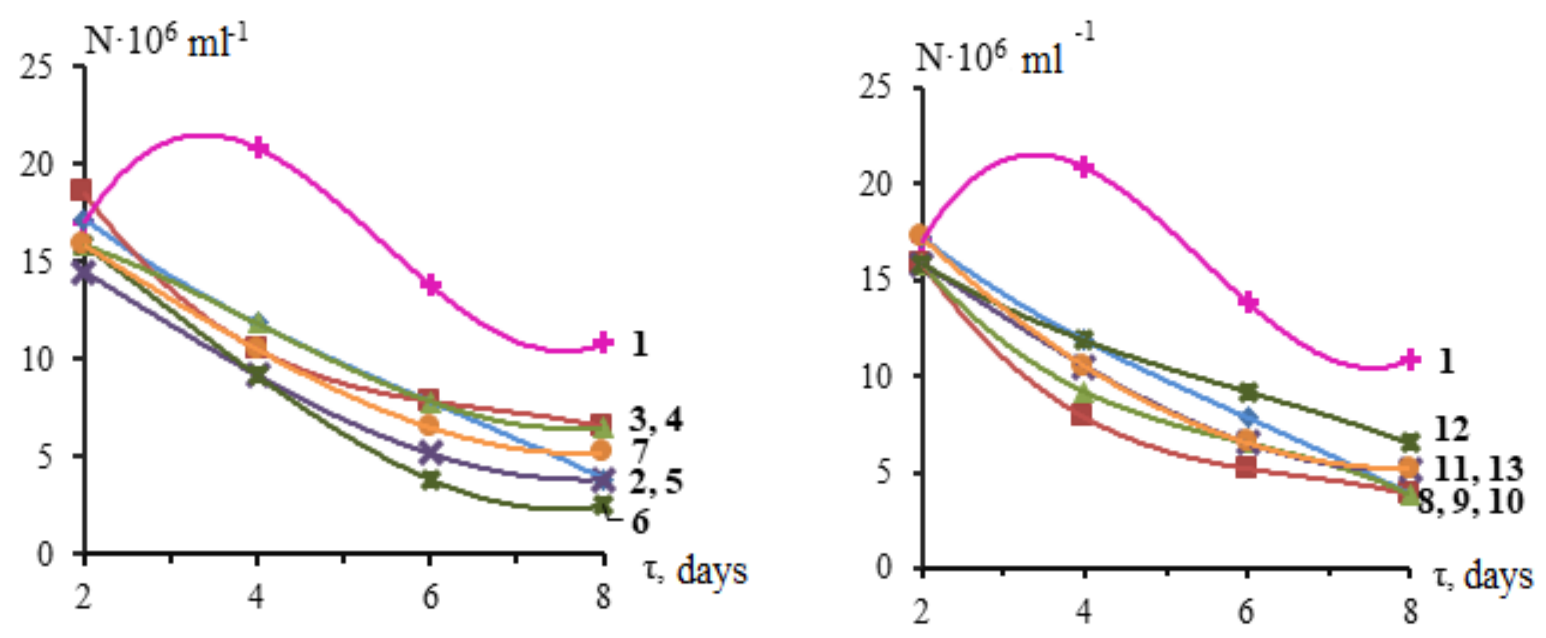

Figure 2. Impact of OC on the growth of SRB, $C_{\mathrm{OC}}=1 \mathrm{mmol} / \mathrm{L}: 1-$ blank; $2-\mathrm{OC} 1 ; 3$ OC $2 ; 4$ - OC $3 ; 5$ - OC $4 ; 6$ - OC5; 7 - OC6; 8 - OC7; 9 - OC $8 ; 10$ - OC9; 11 - OC 10 ; 12 - OC $11 ; 13$ - OC12.

\section{Conclusion}

Thus, all the compounds under study were found to be inhibitors of corrosion and hydrogenation of St3 steel and to inhibit the vital activity of SRB cells. These versatile properties are manifested most efficiently by $\Delta, L$-bis-( $N$-salicylidene asparaginate cobaltate) sodium, $\Delta, L$-bis-( $N$-salicylidene glutaminocobaltate) sodium, $\Delta, L$-bis- $(N$-5Br-salicylidenevalinate cobaltate) sodium, and $\Delta, L$-bis- $(N$ - $5 \mathrm{Br}$-salicylideneleucino cobaltate $)$ sodium. The protective effect of these compounds in gravimetric tests is 90-93\%. They decrease the hydrogen content at a depth of 30 microns 1.8-2.8 fold and the number of cells of sulfatereducing bacteria 2-3 fold, depending on the exposure time. The descriptors obtained by quantum-chemical calculations confirm the experimental results.

\section{References}

1. V.I. Vigdorovich, L.E. Tsygankova, N.V. Shel, M.N. Esina, L.G. Knyazeva, A.V. Boldyrev and Yu.A. Chirkov, Universal inhibitors of hydrogen sulfide and carbon dioxide corrosion of steel for oil production of the Inkorgaz series. Theoretical aspects, practice of use, new in approaches to assessing efficiency, Practice of anti-corrosion protection, 2016, 79, no. 1, 26-42 (in Russian).

2. L.E. Tsygankova, D.O. Chugunov, K.O. Strelnikova and A.A. Kostyak, Inhibitory and bactericidal properties of some compositions of the AMDOR series, Vestnik TGTU, 2015, 2, 376-380 (in Russian).

3. A.I. Gabitov, D.E. Bugay, L.Z. Rolnik and L.K. Kuznetsov, Development of highly effective corrosion inhibitors of complex action as one of the priority directions of world scientific and technological progress, Bashkir Chem. J., 2009, 16, no. 2, 190 (in Russian). 
4. D.L. Rakhmankulov and V.N. Zentsov, Corrosion inhibitors. Fundamentals of production technology for domestic corrosion inhibitors, Inter, Moscow, 2005, p. 346 (in Russian).

5. G.S. Beloglazov, Organic inhibitors of corrosion of metals: quantum chemical study (also inhibitors of hydrogen absorption by steel), LAP LAMBERT Academic Publishing, Saarbrucken, Deutschland, 2013, p. 168.

6. G.S. Beloglazov, Quantum chemical study of organic inhibitors of corrosion and hydrogen absorption. An investigation of the mechanism of bainite transformation in experimental 0.2c-1v-2mn steel, Adv. Mater. Sci., 2012, 12, no. 2, 5-18. doi: $\underline{10.2478 / \mathrm{v} 10077-012-0004-5}$

7. S.A. Teryusheva, G.S. Beloglazov and S.M. Beloglazov, Experimental and Quantum Chemical Study of Quinone Derivatives as Inhibitors of Corrosion and Hydrogen Absorption by Steel, Solid State Phenom., 2012, 183, 249-255. doi: 10.4028/www.scientific.net/SSP.183.249

8. V.I. Vigdorovich and L.E. Tsygankova, Inhibition of hydrogen sulfide and carbon dioxide corrosion of metals. Versatility of inhibitors, Kartek, Moscow, 2011, p. 242 (in Russian).

9. S.M. Beloglazov, Electrochemical hydrogen and metals: absorption, diffusion, and embrittlement prevention in corrosion and electroplating, Nova Science Publishers, USA, 2013, p. 260.

10. T. Clark and J. Wile, A handbook of computational chemistry: A practical guide to chemical structure and energy calculations, Wiley-Interscience, NY, 1985, p. 332.

11. J.B. Foresman and A. Frisch, Exploring Chemistry with Electronic Structure Methods, Gaussian, Wallingford, 2015, p. 303.

12. M.J. Frisch, G.W. Trucks et al, Gaussian 03, Revision B.05, Gaussian, Inc., Pittsburgh PA, 2003.

13. V.F. Traven, Electronic structure and properties of organic molecules, Khimiya, Moscow, 1989, p. 384 (in Russian). 